\title{
Sensitivity of Dobson and Brewer Umkehr ozone profile retrievals to ozone cross-sections and stray light effects
}

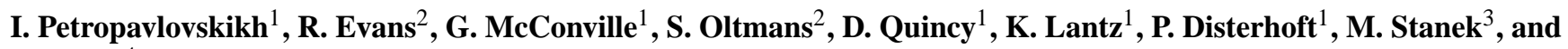 \\ L. Flynn ${ }^{4}$ \\ ${ }^{1}$ Cooperative Institute for Research in Environmental Sciences, University of Colorado, Boulder, Colorado, 80309, USA \\ ${ }^{2}$ NOAA/OAR/ERSL Climate Monitoring Division, 325 Broadway, Boulder, Colorado, 80305, USA \\ ${ }^{3}$ Solar and Ozone Observatory, Czech Hydrometeorological Institute, Hvezdarna 456, \\ 50008 Hradec Kralove, Czech Republic \\ ${ }^{4}$ NOAA/NESDIS/ORA, Camp Springs, MD, USA
}

Received: 23 December 2010 - Published in Atmos. Meas. Tech. Discuss.: 30 March 2011

Revised: 11 August 2011 - Accepted: 2 September 2011 - Published: 9 September 2011

\begin{abstract}
Remote sounding methods are used to derive ozone profile and column information from various groundbased and satellite measurements. Vertical ozone profiles measured in Dobson units (DU) are currently retrieved based on laboratory measurements of the ozone absorption crosssection spectrum between 270 and $400 \mathrm{~nm}$ published in 1985 by Bass and Paur (BP). Recently, the US National Aeronautics and Space Administration (NASA) and the European Space Agency (ESA) proposed using the set of ozone crosssection measurements made at the Daumont laboratory in 1992 (BDM) for revising the Aura Ozone Monitoring Instrument (OMI) and Global Ozone Monitoring Experiment (GOME) satellite ozone profiles and total ozone column retrievals. Dobson Umkehr zenith sky data have been collected by NOAA ground-based stations at Boulder, $\mathrm{CO}$ (BDR) and Mauna Loa Observatory, HI (MLO) since the 1980s. The UMK04 algorithm is based on the BP ozone cross-section data. It is currently used for all Dobson Umkehr data processing submitted to the World Ozone and Ultraviolet radiation Data Centre (WOUDC) under the Global Atmosphere Watch (GAW) program of the World Meteorological Organization (WMO). Ozone profiles are also retrieved from measurements by the Mark IV Brewers operated by the NOAA-EPA Brewer Spectrophotometer UV and Ozone Network (NEUBrew) using a modified UMK04 algorithm (O3BUmkehr v.2.6, Martin Stanek). This paper describes the sensitivity of the Umkehr retrievals with respect to the proposed ozone cross-section changes. It is found that the
\end{abstract}

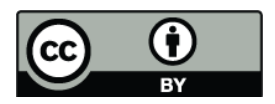

Correspondence to: I. Petropavlovskikh (irina.petro@noaa.gov) ozone cross-section choice only minimally (within the retrieval accuracy) affects the Dobson and the Brewer Umkehr retrievals. On the other hand, significantly larger errors were found in the MLO and Boulder Umkehr ozone data ( -8 and $+5 \%$ bias in stratosphere and troposphere respectively) when the out-of-band (OOB) stray light contribution to the Umkehr measurement is not taken into account (correction is currently not included in the UMK04). The vertical distribution of OOB effect in the retrieved profile can be related to the local ozone climatology, instrument degradation, and optical characteristics of the instrument. Nonetheless, recurring OOB errors do not contribute to the long-term ozone trends.

\section{Introduction}

The record of stations using Dobson instruments in the WOUDC starts in 1924 with one station reporting total ozone values based on measurements of direct-sun irradiance and zenith sky radiance (Dobson and Harrison, 1926). The Dobson network is defined as arrangement between stations reporting information to the common archive while using a common set of guidelines (Dobson, 1957). It has developed from a small set of mostly European sites to approximately 60 stations worldwide by 1962 . That year, a world reference Dobson instrument was defined (W. D. Komhyr, private communication, 2011). It has proven to be a very stable and well maintained network capable of long-term ozone measurements that relies on regular calibration and intercomparison activities within the WMO GAW global ozone observing network (Petropavlovskikh et al., 2008). The Brewer spectrophotometer (Brewer, 1973; Kerr et al., 1985) went into

Published by Copernicus Publications on behalf of the European Geosciences Union. 
service in 1982. The design goals included the elimination of the Dobson "optical wedge", improving stray light performance, the measurement of absolute intensities at individual wavelengths, a reduction in the measurement noise and the improvement of measurement accuracy at low-sun conditions and thereby the improvement of the derived ozone accuracy, while providing automated operation for the Brewer network. The MKIV Brewer design also added new measurement capabilities, such as the capacity to make spectrally resolved Ultra-Violet radiation (Brewer MKIV Spectrophotometer Operators Manual, 1999; Cappellani and Kochler, 1999). Unfortunately, some of the design features lead to instability of its optical system due to the degradation of one of the optical filters used in MKII, MKIV and MKV versions of the instrument (Bennet and McBride, 1964; Kimlin et al., 2003). Therefore, regular calibration of the Brewer instruments in the network and post-correction of measurements is done every $2 \mathrm{yr}$ (Early et al., 1998; Lantz et al., 2002; Kimlin et al., 2005; Petropavlovskikh et al., 2007). The NEUBrew operational network (http://www.esrl.noaa. gov/gmd/grad/neubrew) has relied on the original calibration against the Brewer 017 traveling standard since 2006, with continuous data corrections applied based to the internal reference lamp or Langley plots (description of procedures can be found at the website). The Dobson network carries out intercomparisons and calibration of network instruments every $4 \mathrm{yr}$, while regional standards are calibrated every $3 \mathrm{yr}$.

Comparisons with other measurements (i.e. ozone sonds, LIDAR, microwave and satellite instruments) are done routinely during Dobson Umkehr intercomparisons, at the stations with co-incident measurements by different systems, and reports are typically published under the WMO program. Recently published paper by Nair et al. (2011) compares Dobson Umkehr, lidar, ozone balloon and several satellite ozone profiles over the Haute-Provence Observatory ground station in France. Authors describe biases between coincident Umkehr and lidar data that are similar in magnitude to the errors discussed in this paper and are most likely associated with the stray light contribution to the Dobson measurements.

Among important shortcomings of both the Dobson and Brewer systems is the contribution of the out-ofband (OOB) light in Direct-sun, UV and zenith-sky measurements (Dobson, 1968; Lantz et al., 2002; Evans et al., 2009; Petropavlovskikh et al., 2009). With the exception of the Brewer MK III instrument, the rejection of the stray light in Dobson and Brewer MKII and MKIV instruments is approximately five orders of magnitude. It manifests itself as the low intensity spectrum of the solar light that is not completely removed by the optical bandpass of the instrument. Thus, OOB light continues to contribute to the photon count with the maximum contribution from the wavelengths immediately outside of the nominal bandpass. Although the level of the spectrally resolved light that propagates outside of the bandpass seems to have low intensity, the spectrally-integrated OOB contribution might be important for accurate interpretation of Brewer measurements, especially at shorter wavelength channels, where the contribution of the OOB light is a greater proportion of the received light due to ozone absorption spectra and long optical path at large SZAs. When contribution of the OOB stray light becomes significant it affects the retrieved ozone column and its vertical distribution. The stray light effect is also important in the calculation of the daily Solar UV doses, where a correction for the effect is applied; however, it is not the subject of this paper (see more in Lantz et al., 2002).

Prior to the satellite era regular Umkehr observations from a few sites were the only source of information for ozone in the upper stratosphere. The first satellite measurements began in the 1970s when the Back-scatter UV (BUV) instrument was launched aboard the Nimbus-7 satellite in 1978 (Reinsel, 1982; McPeters et al., 1984) followed by the SBUV(2) series launched on various NOAA satellites (Flynn et al., 2009) and the future Ozone Mapping Profiler Suite (OMPS) of the NPOESS program (Flynn et al., 2004; Fleig et al., 1990). To date, data from these satellite-based instruments have been analyzed using Bass and Paur ozone absorption cross-sections (Bass and Paur, 1985; Orphal, 2003). Recently, the US National Aeronautics and Space Administration (NASA) and the European Space Agency (ESA) proposed using the set of ozone absorption cross-section measurements made at the Daumont laboratory in 1992 (BDM) for revising satellite ozone profiles and total ozone column retrievals from the Aura OMI (Levelt et al., 2006), the ENVISAT Scanning Imaging Absorption spectroMeter for Atmospheric CartograpHY (SCIAMACHY) (Bovensmann et al., 1999), and METOP GOME-2 (Burrows et al., 1999a; Munro et al., 2006) measurements. Therefore, the joint ad hoc commission "ACSO" (Absorption Cross Sections of Ozone, Burrows et al., 1999b) was created by the World Meteorological Organization (WMO) (Scientific Advisory Group (SAG) of the Global Atmosphere Watch (GAW) and IGACO-O3/UV and the International Ozone Commission IO3C) of the International Association of Meteorology and Atmospheric Sciences (IAMAS). The ACSO's primary responsibility was to investigate the effects of various ozone absorption cross-sections on the currently available remote sensing retrieved ozone products (Dobson, Brewer, LIDAR, DOAS, SAOZ, and various satellites taking measurements in the UV, Visible and Infra-red spectral ranges). Several datasets under consideration are listed on the webpage created by the ACSO (http://igaco-o3.fmi.fi/ACSO/ cross_sections.html). These datasets were produced under different equipment settings, measuring methods, different spectral resolution, and at various atmospheric temperatures (Orphal, 2003).

This paper investigates how the choice of ozone absorption cross-sections from two datasets (PB and BDM) affects the retrieved ozone profiles from ground-based Brewer or Dobson spectrophotometer measurements using the Umkehr 
technique. The calculation of the zenith sky radiance utilizes temperature dependent ozone absorption cross section in the radiative transfer calculation and weights the radiance by the instrument's slit function. This paper also investigates the error due to the stray-light (OOB) on the calculated zenith sky radiance and compares this to the differences caused by the choice of ozone absorption cross sections.

\section{Background}

Ozone profiles can be retrieved from zenith-sky measurements made by Dobson or Brewer spectrophotometers. The Umkehr $\mathrm{N}$-value measured when the sun is at a particular elevation or solar zenith angle (SZA) is described by the first term in the right side of Eq. (1).

$N_{\mathrm{SZA}} \equiv \log \left(F_{\mathrm{SZA}}^{L_{2}} / F_{\mathrm{SZA}}^{L_{1}}\right)-\log \left(F_{0}^{L_{2}} / F_{0}^{L_{1}}\right)$

where: $F_{\mathrm{SZA}}=I_{\mathrm{SZA}} \times K_{*} \mathrm{ETC}$, is used to simulate the measured radiance, where $I_{\mathrm{SZA}}$ is zenith sky radiance normalized to the top of the atmosphere (attenuation of the scattered light through the atmosphere), $K$ is instrumental constant or instrument transfer function, and ETC is the extra-terrestrial constant (obtained through Langley type tests).

$F_{\mathrm{SZA}}^{L 2}$ or $L 1$ is the Umkehr measurement at the nominal SZA at the longer $\left(L_{2}\right)$ or shorter $\left(L_{1}\right)$ wavelength channel.

$F_{0}^{L 2}$ or $L 1$ is the Umkehr measurement at $L_{2}$ or $L_{1}$ spectral channel taken at the highest SZAs

$F_{\mathrm{SZA}}^{L 2}$ or ${ }^{L 1}$ represents the signal (intensity of the zenith skylight) detected by the instrument at an individual channel (Brewer) or relative difference in signals detected by Dobson in the pair of spectral channels (C-pair). The actual measurement can be a photon count (Brewer) or position of the Rdial (Dobson) that are then converted to the atmospheric radiances through calibration procedures. The extra terrestrial solar flux measured by other instrument (for example, Atlas1, 2 or 3 mission used SUSIM instrument to observe sun in 1992, 1993 and 1994 respectively during the space shuttle mission, Van Hoosier, 1996) can be used to make radiance simulations. Since neither instrumental constant $K$ nor ETC are known for Umkehr measurements, the retrieval relies on subtraction of the nominal measurement, $F_{0}^{L 2}$ or $L 1$, from the other Umkehr measurements (at different SZA), which effectively removes the $K$ and ETC unknowns.

Prior to the ozone profile retrieval Umkehr $\mathrm{N}$-values were typically scaled (normalized) to the measurement taken at the highest of the nominal SZAs (typically at 60 or 70 degrees). The normalization procedure (second term in right side of the Eq. 1) serves to minimize the adverse effects of factors such as daily changes in solar flux, and maintains nearly constant optical throughput during the entire set of Umkehr measurements (a sequence of morning or afternoon zenith sky measurements taken when the sun elevation changes between 60 and 90 degrees SZA) under the assumption of static atmospheric conditions. When a single set of

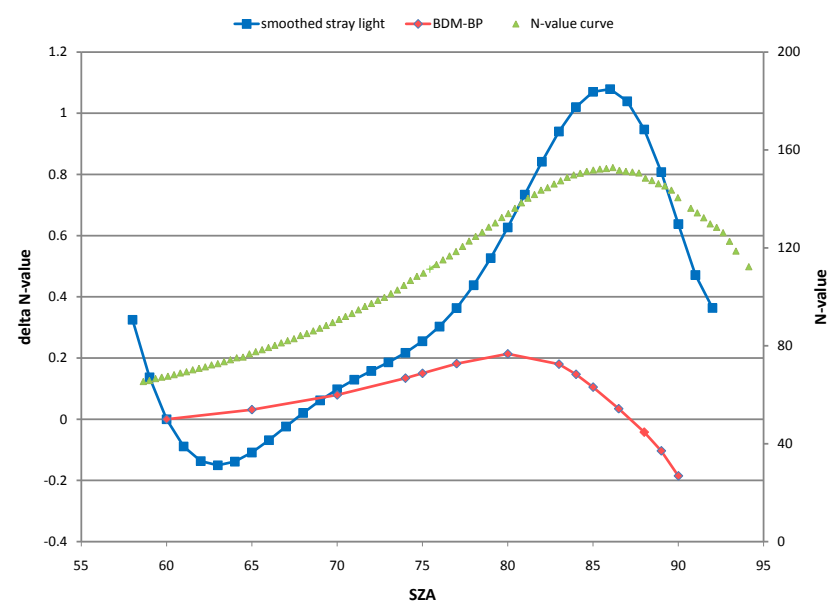

Fig. 1. Solar zenith angle shape of the out-of-band light contribution to Umkehr measurements by Dobson No. 065 obtained in Boulder on 4 April 2008. Total ozone is 360 DU. The blue squares are smoothed change in Dobson C-pair measurements (delta N-values, left-side axes) associated with the out-of-band stray light compared to measurements without stray-light contribution, whereas green triangles show measured Umkehr curve ( $\mathrm{N}$-value, axes on the right side). The difference between $\mathrm{N}$-values simulated with $\mathrm{BP}$ and BDM ozone absorption cross-sections is shown as red diamonds (delta $\mathrm{N}$-value, left-side axes).

Umkehr measurements is plotted as a function of SZA, it is called an Umkehr curve (green symbols in Fig. 1).

The characteristics of the Dobson instrument, its calibration and data processing details are described elsewhere (Dobson and Normand, 1962; Komhyr and Evans, 2006). The Dobson Umkehr measurements considered here are composed of the ratio of the intensities of light detected at the C-pair wavelengths that are centred at $311.5 \mathrm{~nm}$ (strong ozone absorption) and $332.4 \mathrm{~nm}$ (weak ozone absorption). The Umkehr curve is recorded while the solar zenith angle changes between sixty degrees and approximately ninety degrees (Mateer and DeLuisi, 1992; Petropavlovskikh et al., 2005a).

The Brewer instrument makes zenith sky measurement by recording the intensities of polarized zenith-sky light at five wavelengths nearly simultaneously in two, partially overlapping, wavelength bands. The optics and instrumental characteristics of the Brewer spectrophotometer are described elsewhere (Kerr et al., 1985; Kerr and McElroy, 1995; Kerr, 2002; Grobner and Kerr, 2001 and Cede et al., 2003, 2006). The ratio of measured intensitiescentred at $\sim 310 \mathrm{~nm}\left(L_{1}\right)$ and $\sim 326 \mathrm{~nm}\left(L_{2}\right)$ can be combined to create an Umkehr curve. A somewhat shorter range of solar zenith angles (7092.5 degrees) is selected in the Brewer measurement schedule.

The information content of the measured Umkehr curve is analyzed by the optimal statistical approach (Rodgers, 2000) where a priori information about the vertical distribution of 


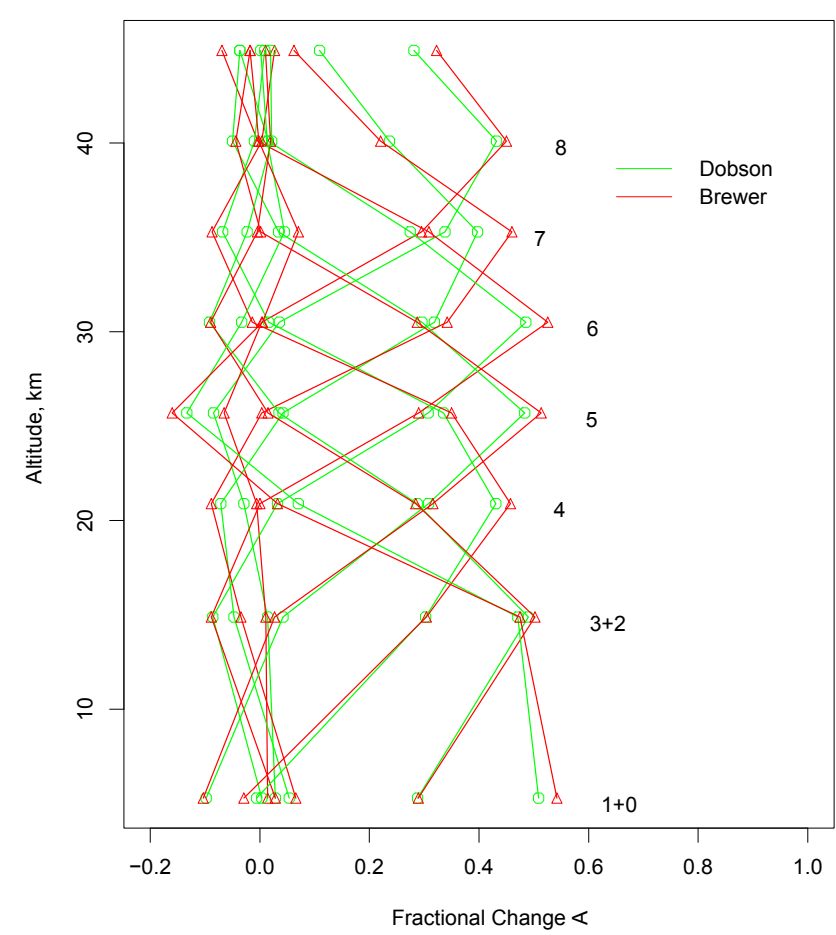

Fig. 2. Averaging kernels for Dobson (green) and Brewer (red) are shown as fractional change vs. altitude. Corresponding Umkehr layers are indicated at the maximum of the AK.

ozone and its natural variability are used for the iterative solution expected under pre-determined conditions. Figure 2 shows an example of the AK for the Dobson (black) and Brewer (red) middle latitude climatological ozone profile with $325 \mathrm{DU}$ column value. The AK shows the sensitivity of the retrieval to ozone vertical information. The AK plot shows that information in the layer is sensed at $\sim 60-70 \%$, while the rest of the information comes from the adjacent layers. It also explains how the algorithm applies vertical smoothing to the retrieved ozone profile. Long-term Umkehr data from the Dobson instrument 061 located in Boulder, CO were processed using UMK04 code (Petropavlovskikh et al., 2005a), and the retrieved ozone profile time series were used in the analysis for this paper.

Umkehr measurements from several Brewer instruments located near Boulder, $\mathrm{CO}$ are used to demonstrate the sensitivity of Brewer ozone profile retrievals to the choice of an ozone absorption cross section dataset and individual stray light contribution. More information on the Brewer Mark IV operations over the continental US sites, Umkehr measurements (contained in the so-called B-files) and retrieved ozone profiles can be found at the NOAA-EPA Brewer Spectrophotometer UV and Ozone Network (NEUBrew) data centre (HU www.esrl.noaa.gov/gmd/grad/neubrew UH). Ozone profiles are retrieved from the classic Brewer Umkehr measurements (manufacturer's supplied set of operational commands and programs) using a modified UMK04 algorithm
(PC code, O3BUmkehr v.2.5, developed by Martin Stanek) (Petropavlovskikh et al., 2005b, 2007). In addition, longterm Umkehr measurements were taken by the Brewer MKII instrument \#9 operated by Environment Canada (EC) at Mauna Loa observatory, Hawaii between 1998 and 2005 (V. Fioletov of EC, private communication, 2006). The data were processed by the O3BUmkehr algorithm, and results of sensitivity analyses are compared with results obtained from the NEUBrew MKIV Umkehr measurements.

\section{Bandpasses and spectroscopic dataset}

Slit functions for individual bandpasses of the world standard Dobson spectrophotometer (83) were experimentally determined by Komhyr in 1982 using a model 783 McPherson spectrophotometer (Komhyr, 1982, Komhyr et al., 1993) and accepted as standard for all Dobson instruments deployed worldwide (Komhyr et al., 1989). Slit function (SF) for the core bandpass is centred at the nominal wavelength $\left(\lambda_{0}^{\text {short }}\right.$ or $\lambda_{0}^{\text {long }}$ ) and is approximated as a triangular shape for the shorter wavelength of the standard Umkehr pair, while the shape of the slit function at the longer wavelength is a trapezoid. In 1991, the International Ozone Commission under the International Association of Meteorology and Atmospheric Sciences (IAMAS) accepted the effective ozone cross sections for processing of the Dobson total ozone data. These ozone cross sections were based on the convolution of the Bass-Paur (BP) ozone absorption coefficient data (Bass and Paur, 1985) and the SFs determined for Dobson instrument \#83.

The matching of the retrieved ozone profile to the measured Umkehr curve is based on the radiative-transfer model (or forward model) that is designed to simulate the zenith sky radiance at the surface under conditions matching those during observations. The spectrally resolved radiance is calculated as downward UV radiation emitted by the Sun from the nominal SZA. From this, the amount of radiation attenuated by molecular scattering and ozone absorption under similar climatological conditions is used as the first guess. The ozone absorption coefficients and their sensitivity to temperature (second degree polynomial fit) are determined from laboratory measurements by Bass and Paur (Bass and Paur, 1985; Paur and Bass, 1985) or Brion, Daumont and Molicet (Daumont et al., 1992; Brion et al., 1993; Malicet et al., 1995; or BDM for further reference). The convolution of the spectrally resolved Solar zenith sky radiation $\left(F_{\mathrm{SZA}}(\lambda)\right)$ with bandpass SF of the spectral shape and width (SFW) determined for slit $L\left(\operatorname{SF}^{L}\left(\lambda-\lambda_{0}^{L}\right)\right)$ describes the Brewer or Dobson zenith sky measurement at a selected SZA:

$$
F_{\mathrm{SZA}}^{L}=\int_{\lambda_{0}-\mathrm{SFW}}^{\lambda_{0}+\mathrm{SFW}} F_{\mathrm{SZA}}(\lambda) \times \mathrm{SF}^{L}\left(\lambda-\lambda_{0}^{L}\right)
$$




$$
\times d \lambda / \int_{\lambda_{0}-\mathrm{SFW}}^{\lambda_{0}+\mathrm{SFW}} \mathrm{SF}^{L}\left(\lambda-\lambda_{0}^{L}\right) \times d \lambda
$$

Therefore, an accurate knowledge of the bandpass spectral shape and position are important for the successful simulation of Umkehr measurements and ozone profile retrieval. This paper addresses the effect of uncertainties in the ozone absorption spectrum and its temperature dependence on results of the forward model simulations for Dobson and Brewer Umkehr measurements, and thus their retrieved ozone profile.

Simulations of spectrally resolved zenith sky intensity $\left(F_{\text {SZA }}(\lambda)\right)$ attenuated by molecular scattering and ozone absorption were performed according to Eq. (2) while using both (BP and BDM) sets of ozone absorption cross-section data (and BDM). The spectrally resolved zenith sky radiances were calculated according to the Eq. (2). The differences in zenith sky radiances within the bandpass fluctuate between -1 and $+3 \%$, but are mostly canceled out during integration over the bandpass spectral range. The results are also highly sensitive to the amount of ozone in the overhead column, temperature and SZA.

The temperature dependence of the ozone cross section varies spectrally, which is a concern when the $\mathrm{BP}$ ozone cross section data-set is used in the ozone retrievals (Kerr, 2002; Orphal, 2003). Although, the Dobson and Brewer wavelengths where selected for regions where the ozone absorption cross sections have reduced temperature sensitivity, the combination of spectral channels were primary chosen to minimize interference from other optical and instrumental parameters and do not completely remove the temperature effect from the derived ozone profile or column. The Brewer design came much later (in 1980s) than the Dobson (in 1920s), after more precise laboratory methodology for determining ozone absorption cross-sections were available, and thus a better knowledge of the spectral dependence of ozone absorption was known during its design. On the other hand, Dobson's wide bandpasses help to more effectively average out spectral uncertainty of the analyzed data. Figure 3 shows the spectral dependence of the linear $(a, b)$ and quadratic (c) terms of the temperature fit for the bandpassweighted BP and BDM ozone cross-section dataset. The figures denote spectral differences between the BP and BDM data sets. However, due to the wide range of wavelengths transmitted through the Dobson bandpass the differences in simulated $\mathrm{N}$-values are not large, and only slightly affect the retrieval solution.

\section{Stray-light contribution in Dobson and Brewer Umkehr measurements}

The change between the two ozone absorption cross-section datasets has a smaller effect on simulated Umkehr $\mathrm{N}$ values than the effect of the out of-band (OOB) stray light
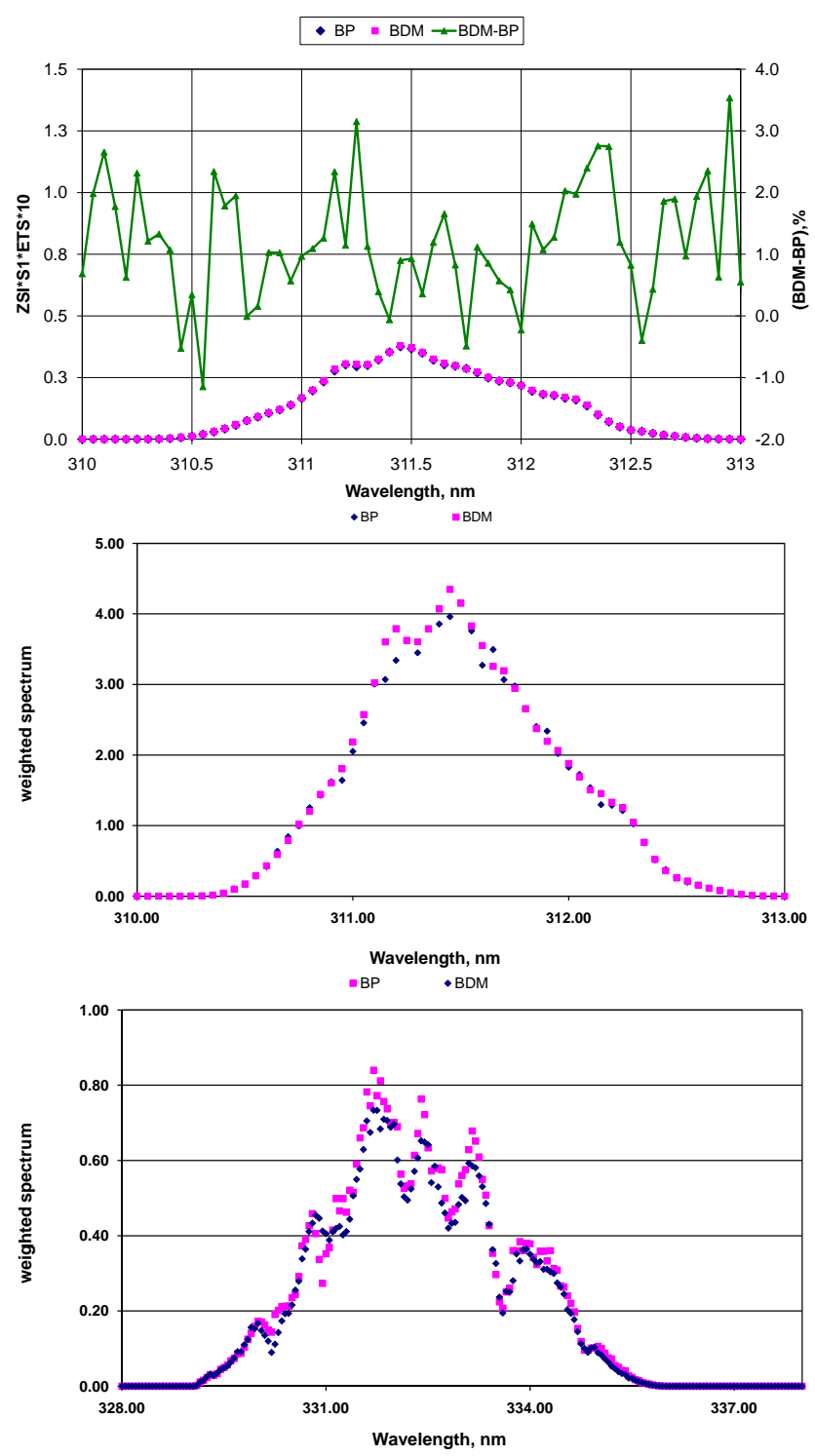

Fig. 3. (a) Shows simulated zenith-sky intensity after applying the Dobson bandpass function. Results are shown for simulations of the solar radiation scattered at 85 degrees SZA and absorbed by 325 DU ozone column with a vertical distribution taken from the middle latitude climatological profile. Two sets of calculations are done based on the BP (blue) and BDM (purple) ozone cross-section datasets. The spectrally-resolved percent difference between the two simulations is shown as the green line (right side scale) over the spectral range of the short Dobson slit. (b) Temperature dependence of BP (blue) and BDM (purple) cross-sections at shorter Dobson wavelengths is shown for linear term of temperature polynomial fit weighted by Dobson band-pass. (c) The same as (b), but for longer wavelength.

(Petropavlovskikh et al., 2009). OOB effect on Umkehr measurements at Dobson and Brewer wavelengths other than Cpair (see description of Dobson and Brewer pair of wavelengths in Sect. 2) is not discussed in this paper. Figure 1 
shows a measured Umkehr curve taken by Dobson 065 in Boulder on 4 April 2008 (green triangles, axes are on the right side). On this day, the total ozone column derived from the direct-sun Dobson measurements (Dobson, 1962; Komhyr and Evans, 2006) was 360 DU (Dobson Units). Also shown is the contribution of the OOB (blue squares) to Umkehr measurements. The OOB $\mathrm{N}$-values were recorded by using a WG320 spectral filter that is mostly opaque in the spectral range of the Dobson C-pair short wavelength bandpass (Fig. 6 in Evans et al., 2009). In addition, the Dobson optical design restricts the incoming light to wavelengths shorter than $\sim 400 \mathrm{~nm}$ with an internal cobalt filter, and by the response of the photomultiplier tube (Fig. 5 in Evans et al., 2009). The WG320 filter was placed in front of the zenith sky entrance of the instrument such that the measured spectrum of the solar radiation was completely restricted to the radiation at wavelengths shorter than $\sim 340 \mathrm{~nm}$ and partially restricted to the wavelengths just outside of the nominal bandpass spectral region. The concept was that the filter would remove the shortwave length light from the short wavelength bandpass of the $\mathrm{C}$ pair, and that any current remaining is from the OOB light. Although the filter did not completely remove all of the light within the short bandpass it was useful to estimate the range of the OOB effect on Umkehr measurements. The spectral shape of the OOB contribution to Umkehr measurements is controlled by the gradient in ozone absorption spectra, SZA and total ozone amount. Therefore, changes in $\mathrm{N}$-values are SZA dependent (smoothed data are shown in blue). The minimum in the stay light curve of Delta-N in Fig. 1 at 60-65 SZA is not yet explained. In addition, the difference between $\mathrm{N}$-values simulated with $\mathrm{BP}$ and BDM ozone absorption cross-sections is shown in Fig. 1 (red diamonds) for comparisons. The effect of cross-section changes on $\mathrm{N}$-values appears to be relatively small, but the effect propagates through the retrieval process and changes the retrieved ozone profile.

Stray light effects in Brewer MK II and MKIV instruments appear to be of a similar magnitude to that found in Dobson measurements, whereas MKIII instruments use a double monochromator with higher line density gratings that results in efficient rejection of the OOB light. The light measured in the wings of the slit function in a MKIII is below $10^{-6}$ of the bandpass center wavelength transmission as compared to $10^{-5}$ and $10^{-4}$ opacity in Dobson and Brewer MKIV respectively. Several Brewer MKIV bandpasses and stray light rejection were measured during The Fourth North American Interagency Intercomparisons of Ultraviolet Monitoring near Boulder, Colorado, in 1997 and published by Lantz et al. (2002). The slit functions were measured with the $\mathrm{HeCd}$ laser (Omnichrome Model 3056, single line at $325.029 \mathrm{~nm}$ and a nominal power of $18 \mathrm{~mW}$ ). Figure 4 shows examples of bandpasses as function of wavelength for two Brewer instruments: NEUBrew MKIV \#101 and Environment Canada's MKII, \#009. The slit function contains the core (bandpass) spectral area and the extended wings. Note that the right side

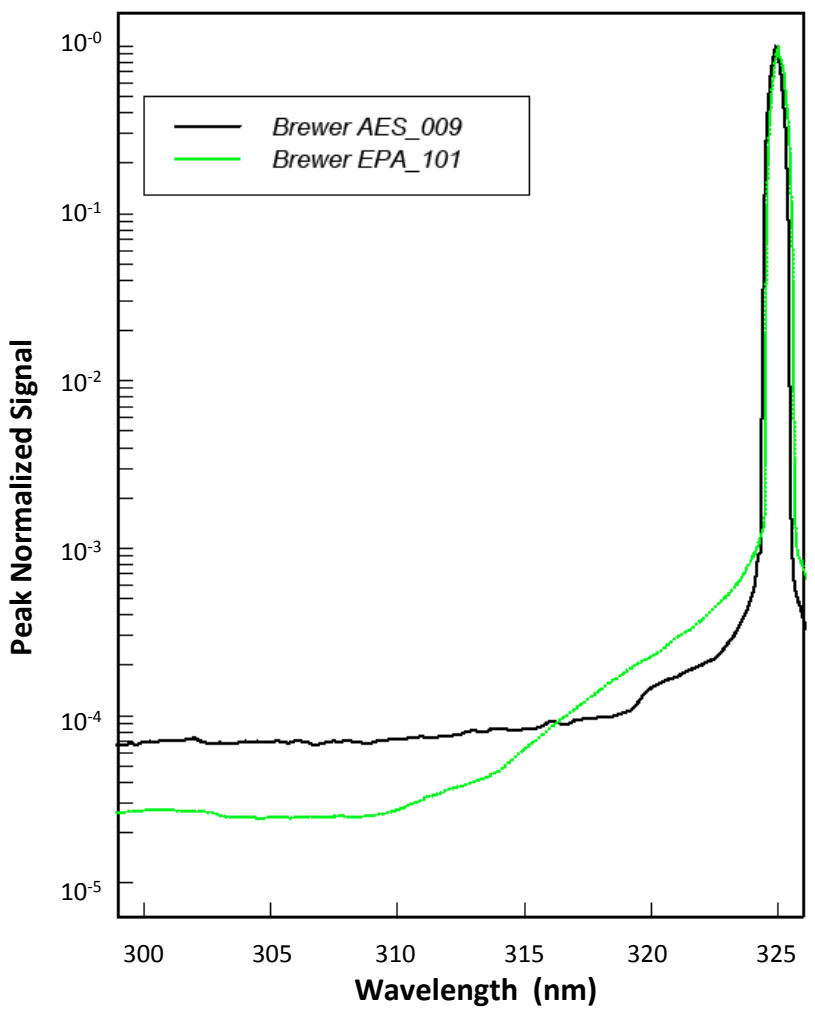

Fig. 4. Slit scattering functions for two Brewers, EC MkII Brewer \# 9 (black) and NEUBrew MkIV Brewer \#101 (green), measured through slit 1 during 1997 Intercomparison of Ultraviolet Monitoring Spectroradiometers (Lantz et al., 2002) (data from: ftp: //ftp.srrb.noaa.gov/pub/data/CUCF/).

of the slit function (not shown) has a symmetric shape. The shape of the bandpass for Brewer \#101 shown in Fig. 4 is representative for a slit in the single (1200 lines $\mathrm{mm}^{-1}$ holographic) grating MKIV instruments (Brewer MKIV Spectrophotometer operators manual, 1999) that are deployed in the NEUBrew network. The $\sim 3 \times 10^{-5}$ and $6 \times 10^{-5}$ level of the light respectively measured at the slit function wings for Brewers \#101 and \#114 (not shown) indicates that two identically configured instruments can have different OOB light rejection. The OOB contribution to the MKIV and MKII Brewer Umkehr measurements is comparable to the $\sim 2 \times 10^{-5}$ rejection level of Dobson C-pair N-values. The OOB light from longer wavelengths is reduced in the Brewer MKIV by the use of a solar blind filter (SBF), which is made of nickel sulphate hexahydrate $\left(\mathrm{NiSO}_{4} 6 \mathrm{H}_{2} \mathrm{O}\right)$ crystal placed between two UV-transmitting, colored glass filters (similar to Schott UG5 or UG11, private communications with P. Disterhoft). The SBF is designed to block wavelengths longer than $363 \mathrm{~nm}$ from entering the PMT's (photomultiplier tube) cathode, which by itself is insensitive to the near-infrared solar spectrum. Major optical characteristics of Dobson and Brewer instruments are summarized in Table 1. What is most 
relevant to this discussion is the spectral range of the zenith sky radiances transmitted through the bandpasses of two selected Brewer channels (centered at $\sim 310$ and $\sim 326 \mathrm{~nm}$, see details described above), their width, shape, stray light contribution, and corresponding ozone absorption cross-section structure over the individual bandpass spectral ranges. In order to simulate N-values for the contribution of SZA dependent stray light similar to that of the Dobson instrument (green symbols on Fig. 1), the following procedure is developed. Both Brewer and Dobson OOB correction are simulated by using full and nominal bandpass (with and without extended spectral wings) for convolution with the spectrally resolved zenith sky radiances (Eq. 2). The radiances are simulated by the TOMRAD radiative transfer code, and look-up tables are created based on the set of standard ozone profiles (see Petropavlovskikh et al., 2005a for further details). The slit function shape for the MKIV Brewer is chosen to have slightly higher levels at the wings $\left(10^{-4}\right.$ level) than was reported in Lantz et al. (2002) to more consistently represent levels of stray light produced by other instruments used in the NEUBrew network. More detailed information about the optical characteristics of MKIV Brewer spectrophotometers is available from the various documents posted under the "Algorithm and Procedure" section at the NEUBrew webpage (http://esrl.noaa.gov/gmd/grad/neubrew/index.jsp). In the absence of exact measurements of individual instrument slit functions and for simplicity of analyses the OOB corrections for Brewer MKII data processing is chosen to be similar to the above described OOB levels for the MKIV instrument.

Figure 5 shows the differences found between the measurements and simulations without (solid lines) and with (dashed lines) stray light corrections (OOB). This is an example of a single day of measurements taken in Boulder at the NOAA David Skaggs Research Center (DSRC) and at Table Mountain Test Facility (TMTF) during intercomparisons on 20 September 2007. The top panel shows results for Umkehr measurements performed by Dobson instruments, and the bottom panel shows results for Brewer spectrophotometers. Among participating Dobson instruments are Boulder station instrument \#61, Secondary world standard \#65, World standard instrument \#83, JMA (Japan Meteorological Agency) travelling standard instrument \#116. The $\mathrm{N}$-values from look-up tables are interpolated to match the $271 \mathrm{DU}$ total ozone value, which is the average of the total ozone (TO) values from four Dobson and five Brewer instruments. An additional correction is applied to account for ozone profile differences between climatology and actual ozone profile observed on the day of measurements. The reference (observed) ozone profile is a combination of the ozone profile above $\sim 10 \mathrm{hPa}$ pressure level that was selected from the Aura Microwave Limb Sounder (Froidevaux, 2008) satellite global dataset for the Boulder station overpass criteria, and the NOAA/ESRL ozone sounding profile below $\sim 10 \mathrm{hPa}$ pressure level measured over Boulder, $\mathrm{CO}$ on the day of

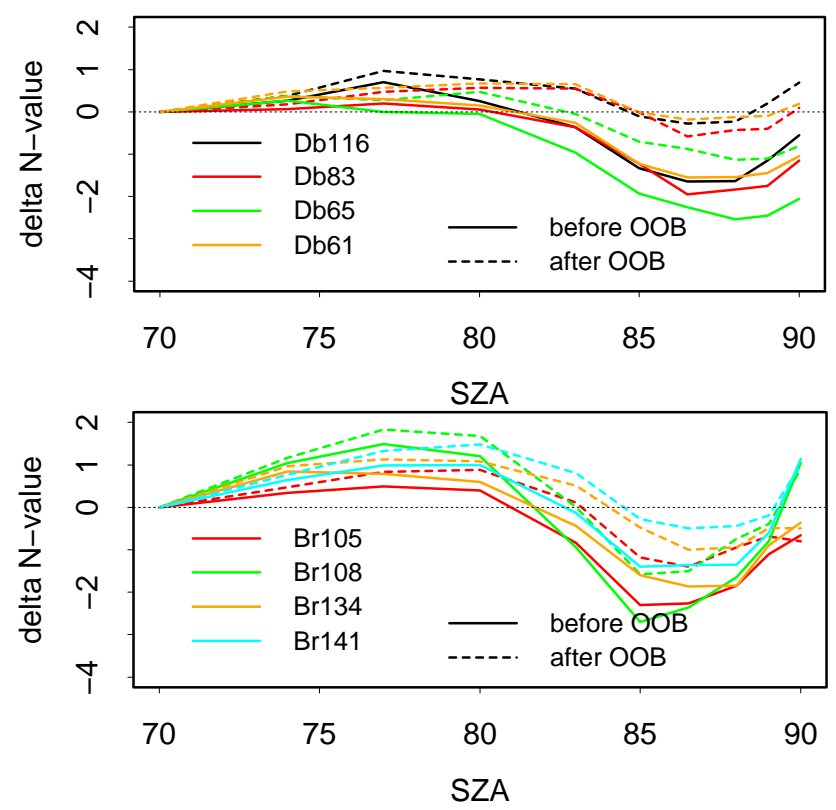

Fig. 5. Difference between observed and simulated Umkehr Nvalues as function of SZA. Solid and dashed lines represent Umkehr simulations prior and after stray light corrections (OOB) respectively. The Umkehr observations were recorded on 20 September 2007 in Boulder, CO and at the Table Mountain Test Facility located near Boulder, CO. (a) Results are demonstrated for Dobson Umkehr measurements taken by NOAA instruments \#83, 61 and 65, and by JMA Dobson \# 116; (b) the same as (a), but for Brewer Mark IV instruments that perform routine measurements as part of the NEUBrew network (instrument numbers are given in the legend).

intercomparisons. The total-ozone-based Jacobians (function of changes in the $\mathrm{N}$-value due to the change in ozone profile) is used to correct simulated climatological Dobson and Brewer Umkehr N-values to account for the observed vertical distribution of ozone. Still, Fig. 5 shows that corrections for ozone profile do not completely remove the SZA-dependent residual differences between the simulated and observed $\mathrm{N}$ values. Figure 5 also show that stray light corrections to Umkehr simulations are required to successfully fit the observed $\mathrm{N}$-values and thereby retrieve the reference ozone profile.

\section{Effects on Dobson and Brewer Umkehr ozone profile retrieval}

The impact of changing ozone cross-sections and their associated temperature dependence on retrieved ozone profiles was examined using Dobson and Brewer Umkehr data. The temperature dependency is spectrally different in BP and BDM datasets. The Umkehr ozone profile is retrieved with a single standard temperature profile and then a posteriori corrected to account for the departure of the true temperature 
Table 1. Optical characteristics of the Dobson and Brewer Umkehr system.

\begin{tabular}{lll}
\hline & Dobson & Brewer \\
\hline $\begin{array}{l}\text { Spectral channels }(\mathrm{nm}) \\
\text { Spectral bandpass }\end{array}$ & $\begin{array}{l}311.4 / 332.5 \\
\text { Wide. Short channel: triangular 1.5 FWHM } \\
\text { Long channel: trapezoid, about } 3.8 \mathrm{~nm} \text { at the } \\
\text { base and and } 2 \mathrm{~nm} \text { at the top } \\
\text { Cobalt filter (cuts off light above } \sim 360 \mathrm{~nm})\end{array}$ & $\begin{array}{l}310.1 / 326.5 \\
\text { Narrow. Both channels have similar triangle shape, } \\
\sim 0.6 \mathrm{~nm} \text { FWHM }\end{array}$ \\
& $\begin{array}{l}\text { Double: Grating, PMT set zero below 250 nm and } \\
\text { above } 800 \mathrm{~nm}\end{array}$ \\
& $\sim 2 \times 10^{-5}, 0.005 \%$ & $\begin{array}{l}\text { Single: UG-11 and NiSO4 filters }- \text { zero below 280 and } \\
\text { above 330 nm }\end{array}$ \\
Stray light (far field) & Single, class II: $\sim 10^{-4}$ for Mark IV at NEUBrew \\
& Double, Mark III: $\sim 10^{-7}$ for Double B171
\end{tabular}

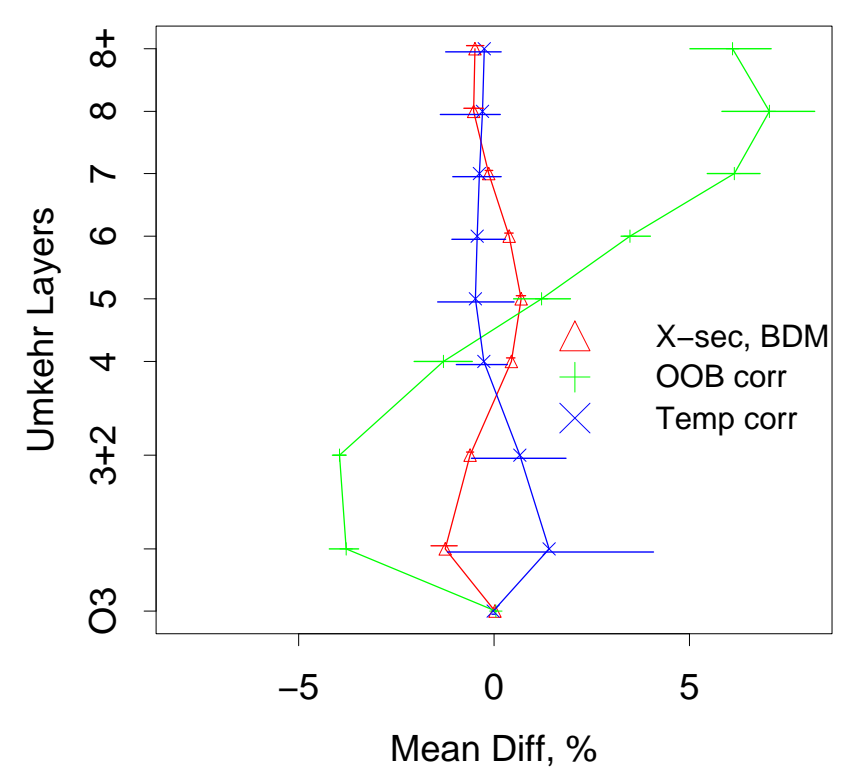

Fig. 6. Ozone profile changes (\% relative to the standard retrieval) retrieved from the Dobson No. 65 measurements in Boulder, CO between 1979 and 2008. The range of data is shown with horizontal lines. Changes in the Umkehr ozone profile are due to the use of the BDM cross-section in place of BP (red), neglect of the stray light contribution (green), and temperature variability in climatological temperature dataset (dark blue).

profile from the assumed, standard profile. The correction depends on the polynomial fit of the ozone cross-section temperature sensitivity. The NRL climatology (Summers and Sawchuck, 1993) provides a set of monthly and zonalaveraged (10-degree band) temperature profiles that are used to choose an appropriate profile for a station based on its latitude and the month of Umkehr observations. As the stray light contribution to the Umkehr measurements is even larger than the effect of the $\mathrm{x}$-section selection (Fig. 1), the change in ozone profile with and without the stray-light correction is analyzed.
Figure 6 shows changes in the Umkehr ozone profiles retrieved from Dobson measurements collected in Boulder, CO between 1979 and 2008. The change in the mean ozone is due to various effects accounted for in the forward model. The red line in Fig. 6 shows changes in the middle latitude ozone profile associated with the change of ozone $\mathrm{x}$-section dataset from BP (standard) to BDM. The mean changes in the retrieved profile are within $\pm 2 \%$. These changes are comparable to the accuracy of Dobson Umkehr ozone profiles retrieved in the stratosphere and considerably less than the accuracy of tropospheric ozone profile, which are less than $10 \%$ (Petropavlovskikh et al., 2005a, b). The errors of the ozone profile retrieval for the Dobson and Brewer Umkehr measurements are derive from the method published by Rodgers (2000, Eq. 3.17 and Eq. 3.19), which involves the measurement uncertainty (known from the instrument characterization) and the profile smoothing technique (vertical resolution based on AK). Typical errors of the Dobson and Brewer Umkehr ozone profile retrieval are provided in Fig. 7 (solid lines). Also included are errors associated with the measurement accuracy and the smoothing errors. The latter are estimates based on the climatological variability of ozone derived from the subset of the SAGE and sounding ozone profiles taken in the month of January between 1988 and 2002 at the Northern middle latitudes (McPeters, Labow and Logan, 2007). The standard deviation error is calculated relative to January middle latitude climatological ozone profile (MLL). The original climatological profiles and variance were converted into Umkehr layers for comparisons.

The sensitivity of the Umkehr profile retrieval to atmospheric temperature variations in the Boulder Dobson dataset (climatological temperature profile for $40-50^{\circ} \mathrm{N}$ ) is of a similar magnitude to the effect of ozone absorption cross section dataset, but of an opposite sign in the stratosphere. The temperature effect is practically identical in both BP and BDM retrieved datasets, and is small as compared to the failure to account for the stray-light contribution in the Umkehr data processing. Figure 6 shows that if a correction of the Umkehr 


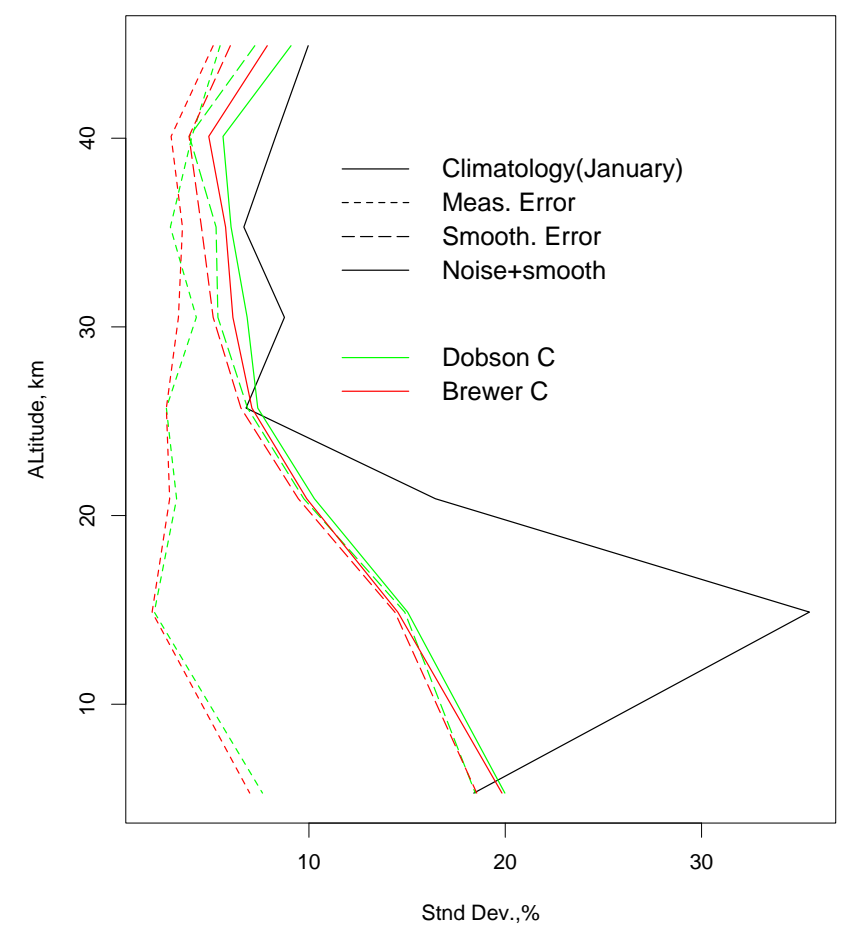

Fig. 7. The errors of ozone retrieval are shown as function of altitude for Dobson (green solid line) and Brewer (red solid line). Also shown separately are errors associated with the measurement (dotted) and smoothing (dashed) uncertainties that contribute to the ozone profile retrieval error. Climatological ozone variability is shown as black line and is taken from the MLL climatology (McPeters et al., 2007) for Northern middle latitude $\left(40-45^{\circ} \mathrm{N}\right)$ and for the month of January. The covariance matrix used in the smoothing error calculations of the Umkehr retrieval is representative of the ozone variability over the middle Northern latitudes based on observations by SAGE II (ozone $\sim$ above $25 \mathrm{~km}$ ) satellite instrument and ozone sonde (ozone below $\sim 25 \mathrm{~km}$ ) profiles collected between 1988 and 2002.

$\mathrm{N}$-values for OOB contribution is applied prior to the retrieval it increases stratospheric ozone by as much as $8 \%$ and decreases tropospheric ozone by $\sim 5 \%$. The OOB effect is thus a more significant change for the Umkehr ozone amount derived in the stratosphere. Similarly, the Brewer Umkehr retrieval algorithm was assessed for its sensitivity to changes in the ozone cross-section, the stray light correction and atmospheric temperature variations. Figure 8 shows averaged results of comparisons between Brewer Umkehr ozone profiles. The data shown in Fig. 8a are derived from the single Brewer (MK II) measurements taken by EC at MLO station in Hawaii from 1998 and until 2005. Figure 8b presents results for the NEUBrew Umkehr ozone profile time series collected by Brewer \#141 (MK IV) at Table Mountain Test Facility, near Boulder, Colorado, between 14 August 2006 and 20 October 2010. Other Brewer instruments at TMTF show very similar patterns to Fig. $7 \mathrm{~b}$ results (not shown).
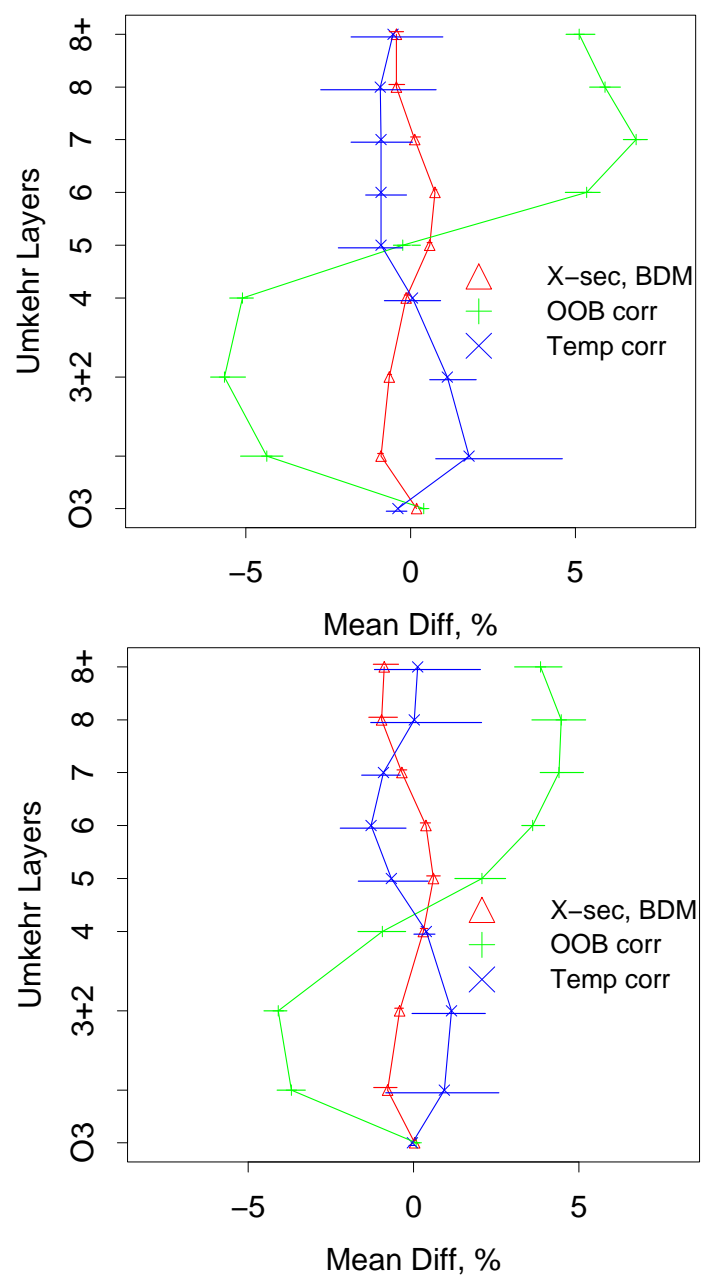

Fig. 8. (a) The same as in Fig. 4, but results are averaged for the EC Brewer Umkehr time series collected at MLO, Hawaii, between 1998 and 2005. (b) The same as in Fig. 6, but results are averaged for the NEUBrew Umkehr ozone profile time series collected by Brewer \#141 at Table Mountain Test Facility, near Boulder, Colorado, between 14 August 2006 and 20 October 2010.

Percent ozone differences in Fig. 8 are calculated relative to the operational ozone profile data product (i.e. the BP ozone $\mathrm{x}$-section dataset, no stray light correction, and climatological stratospheric temperature correction). The magnitude and vertical distribution of the differences derived in Brewer retrieved ozone are fairly similar to analyses of the Dobson Umkehr retrievals (compare to Fig. 6). The changes in the Brewer Umkehr ozone profile that are caused by the choice of ozone $\mathrm{x}$-section dataset are limited to $+/-2 \%$ (shown in red). These changes are comparable to the accuracy of Brewer and Dobson Umkehr ozone profiles retrieved in the stratosphere, while in the troposphere they become less significant due to the tropospheric ozone retrieval accuracy of $\sim 10 \%$. The sensitivity of Brewer ozone profiles to climatological temperature correction is comparable to the average 
effect found in Dobson Umkehr retrieved ozone. The effect of the seasonal variation of temperature profiles on retrieved ozone is presented by the horizontal bars (blue). It shows that tropospheric ozone (layer $0+1$ or partial ozone column derived between surface and $250 \mathrm{hPa}$ pressure) can have zero to $5 \%$ effect depending on the season. The modeled OOB correction produces significant effects on the Brewer Umkehr retrievals. It appears to increase ozone in layers 6,7 and 8 (between $\sim 30$ and $\sim 45 \mathrm{~km}$ ) by less than $5 \%$ in case of NEUBrew data and by more than $5 \%$ in the case of MLO dataset, while tropospheric and low stratospheric ozone is reduced by similar $\%$ amount. The significance of the OOB contribution to the Umkehr measurement and, thus, magnitude of errors in the retrieved ozone profile are strongly affected by the total ozone amount and SZA of observation. Therefore, some differences in the vertical distribution of OOB effects found in two Brewer datasets can be related to the difference in geo-location of Boulder and MLO stations that are affected by different dynamical and long-range transport processed, and latitude-dependent difference in the vertical ozone distribution.

\section{Discussion and conclusion}

Original research by Liu et al. (2007) found that the choice of the BDM ozone $\mathrm{x}$-section would change GOME retrieved total ozone up to $12 \%$. The application of the BDM data for ozone retrieval also improved the spectral residuals of the fit to the satellite measurements. The most recent analyses of the $\mathrm{x}$-section effect on the SCHIAMACHY and GOME-2 retrieved total ozone column revealed a residual bias of $-2 \%$ between the two satellite products (Lerot et al., 2009). However, it was found to be unrelated to the choice of ozone cross section data set (caused by differences in the spectral dependence of x-section's temperature dependence), but rather by differences in the cloud correction algorithm. It was also mentioned that relative spectral shifts and scale factors are applied to the BP spectrum prior to its use in the satellite retrievals. Therefore, sensitivity of the retrieved ozone to the choice of the $\mathrm{x}$-section dataset is tested with respect to the specific temperature sensitivity of each ozone $\mathrm{x}$-section dataset.

As discussed in this paper, the ozone cross-section choice only minimally (within the retrieval accuracy) affects the Dobson and the Brewer Umkehr retrievals. As of 2005, the temperature correction in the Umkehr ozone retrieved profiles has been incorporated in the UMK04 algorithm, and is based on latitude dependence and monthly averaged temperature climatology (Petropavlovskikh et al., 2005a). Inclusion of co-incidentally measured temperature profiles in the Umkehr retrieval could be done, but might not be practical, especially in the assessment of the historical datasets (temperatures are not always available at the beginning of the record), or for the locations where the temperature profiles are not regularly taken. Besides, this study suggests that the temperature sensitivity of the Umkehr retrieval is less than uncertainty of the retrieval. Furthermore, significantly larger errors are found when the OOB stray light contribution to the Umkehr measurement is not taken into account in the retrieval algorithm. The issues and methods of the OOB error correction has been originally described in the Basher (1982) paper and recently addressed in several papers (Miyagawa et al., 2009; Evans et al., 2009; Petropavlovskikh et al., 2009).

The optical characterization of the instrument is required to identify and minimize the instrument dependent OOB contribution. Also, measurements of the slit function could be useful for the proper modeling of instrumental effects and can be used for adjustments of the "effective" (weighted by slit function) ozone cross-sections used in the total ozone calculations. It is also useful for instrument intercomparisons. The method is under development at the NOAA, Boulder (R. Evans, private communications, 2010) in collaboration with the group at the NASA/Goddard (G. Labow) that would allow for the OOB characterization of the Dobson and Brewer instruments. Further development involves determining a feasible "cheap" method for optical characterization of individual instruments. It can rely on the spectrophotometer with high spectral resolution and the system built to "map" the band-pass of the Dobson, which would then determine the stray light contribution based on intercomparisons with other systems that have low stray light characteristics. At this moment the resources are not available to directly measure the stray light in the Dobson instruments. Brewer instrument characterization is more easily done and the methods exist. Once the instrument is characterized, the forward model of the retrieval could be corrected by applying the measured band-pass function for individual instruments. There is a work in progress to assess the similarity of the stray light response between various Dobson instruments. Once this is done, there could be an update on the UMK04 algorithm to include stray light correction.

There is also a greater need for further development, optimization and validation of the Brewer Umkehr algorithm. Although Umkehr measurements are already regularly taken by some instruments, there is no requirement for the archiving of the raw Brewer data. However, there is a WMO and WOUDC organized campaign to encourage such submissions. The Brewer single pair ozone profile retrieval algorithm is readily available for common data processing, but the Umkehr measurements are often not processed and therefore are not methodically archived. Part of the problem is conflicting schedules of different types of measurements taken by Brewers that are dedicated to either UV or ozone programs. Under the grant from the NASA ROSES 2008 Atmospheric composition program, the author is working to develop an algorithm for the Brewer Umkehr data analysis that utilizes multiple spectral channels and requires a smaller range of solar zenith angles for routine observations, which would remove time limitations for data collection and could 
be widely used for routine ozone profile retrieval in addition to UV scans.

Although the stray light in Umkehr measurements creates a bias in the derived ozone profile, it has no significant longterm change and thus does not affect the trend analysis of ozone decline and recovery, which is the main advantage of continuous long-term Umkehr ozone time series. In conclusion, it is important to state that either ozone $\mathrm{x}$-section choice or OOB effects have no statistically significant effect on long-term trends derived from the Umkehr data.

Acknowledgements. The authors wish to thank A. Cede, G. Labow, R. McPeters, and P. K. Bhartia of Goddard Space Flight Center for their assistance in supplying determinations of BDM cross-sections. We would also like to thank T. McElroy and V. Fioletov of the EC for providing MLO Brewer Umkehr data for analysis. The first author would like to express gratitude to M. Stanek of Czech Hydrometeorological Institute, Czech Republic (stanek@chmi.cz), who works tirelessly to modify and improve the O3B umkehr software. This work was supported by the EPA STAR grant EPA-G2006-STAR-D1 and NASA ROSES-2008 Award (NNX09AJ24G).

Edited by: M. Weber

\section{References}

Basher, R. E.: Ozone absorption coefficients' Role in Dobson instrument ozone measurement accuracy, Geophys. Res. Lett., 9(11), 1235-1238, 1982.

Bass, A. M. and Paur, R. J.: The ultraviolet cross-sections of ozone, I, The measurements, in: Atmospheric Ozone, edited by: Zerefos, C. S. and Ghazi, A., and Reidel, D., Norwell, Mass., 606610, 1985.

Bennet, H. E. and McBride, W. R.: Use of filters for suppressing scattered light in spectrometers used in the ultraviolet, Appl. Opt., 3, 919-921, 1964.

Bovensmann, H., Burrows, J. P., Buchwitz, M., Frerick, J., Noël, S., Rozanov, V. V., Chance, K. V., and Goede, A. H. P.: SCIAMACHY - Mission Objectives and Measurement Modes. J. Atmos. Sci., 56, 127-150, 1999.

Brewer MKIV Spectrophotometer Operators Manual: SCI-TEC Instruments Inc, OM-BA-C231 REV B, August 15, 1999.

Brewer, A. W.: A replacement for the Dobson spectrometer?, Pure Appl. Geophys., 106-108, 919-927, 1973.

Brion, J., Chakir, A., Daumont, D., and Malicet, J.: High-resolution laboratory absorption cross sections of $\mathrm{O}_{3}$, Temperature effect, Chem. Phys. Lett., 213(5-6), 610-612, 1993.

Burrows, J. P., Weber, M., Buchwitz, M., Rozanov, V., LadstätterWeissenmayer, A., Richter, A., DeBeek, R., Hoogen, R., Bramstedt, K., Eichmann, K.-U., Eisinger, M., and Perner, D.: The Global Ozone Monitoring Experiment (GOME): mission concept and first scientific results, J. Atmos. Sci., 56, 151-175, 1999a.

Burrows, J., Richter, A., Dehn, A., Deters, B., Himmelmann, S., Voigt, S., and Orphal, J.: Atmospheric remote sensing reference data from GOME: Part 2. Temperature-dependent absorption cross-sections of $\mathrm{O}_{3}$ in the 231-794 nm range, J. Quant. Spectrosc. Ra., 61, 509-517, 1999b.
Cappellani, F. and Kochler, C.: Temperature effects correction in a Brewer MKIV spectrophotometer for solar UV measurements, J. Geophys. Res., 105, 4829-4831, 1999.

Cede, A., Labow, G., Kowalewski, M., Krotkov, N., and Dubovik, O.: Deriving aerosol parameters from absolute UV sky radiance measurements using a Brewer double spectrometer, in: Ultraviolet Ground- and Space-based measurements, Models, and Effects III, 4-6 August 2003, San Diego, USA, Proceedings of SPIE, SPIE-The International Society for Optical Engineering, edited by: Slusser, J. R., Herman, J. R., and Gao, W., 5156, 323-329, 2003.

Cede, A., Kazadzis, S., Kowalewski, M., Bais, A., Kouremeti, N., Blumthaler, M., and Herman, J.: Correction of direct irradiance measurements of Brewer spectrophotometers due to the effect of internal polarization, Geophys. Res. Lett., 33, L02806, doi:10.1029/2005GL024860, 2006.

Daumont, M., Brion, J., Charbonnier, J., and Malicet, J.: Ozone UV spectroscopy, I: Absorption cross-sections at room temperature, J. Atmos. Chem., 15, 145-155, 1992.

Dobson, G. M. B.: Observers' Handbook for the ozone spectrophotometer, Ann. Int. Geophys. Year, 5, Part I., 46-89, 1957.

Dobson, G. M. B.: The evaluation and elimination of errors in the measurement of total ozone when the sun is low, Atmos. Phys., Clarendon Laboratory, University of Oxford, London, Memorandum No. 68.6, 1968.

Dobson, G. M. B. and Harrison, D. N.: Observations of the amount of ozone in the Earth's atmosphere and its relation to other geophysical conditions, Proc. R. Soc. A., 110, 660-693, 1926.

Dobson, G. M. B. and Normand, C. W. B.: Determination of the constants etc. used in the calculation of the amount of ozone from spectrophotometer measurements and of the accuracy of the results, Annals of the International Geophysical Year, XVI, Part II, Pergamon Press, 161-191, 1962.

Early, E. A., Thompson, A., and Disterhoft, P.: A Field Calibration Unit for Ultraviolet Spectroradiometers, Appl. Opt., 37, 66646670, 1998.

Evans, R., McConville, G., Oltmans, S., Petropavlovskikh, I., and Quincy, D.: Measurement of internal stray light within Dobson ozone spectrophotometers, Int. J. Remote Sens., 30(15), 42474258, doi:10.1080/01431160902825057, 2009.

Fleig, A. J., McPeters, R. D., Bhartia, P. K., Schlesinger, B. M., Cebula, R. P., Klenk, K. F., Taylor, S. L., and Heath, D. F.: Nimbus 7 Solar Backscatter Ultraviolet (SBUV) Ozone Products User's Guide, NASA Reference Publication 1234, 1990.

Flynn, L. E., Hornstein, J., and Hilsenrath, E.: The Ozone Mapping and Profiler Suite (OMPS). The next generation of US ozone monitoring instruments, in: Proceedings of the Quadrennial Ozone Symposium, edited by: Zerefos, C., Athens, Greece, 538-539, 2004.

Flynn, L. E., McNamara, D., Beck, C. T., Petropavlovskikh, I., Beach, E., Pachepsky, Y., Li, Y. P., Deland, M., Huan, L. K., Long, C. S., Seftor, C. S., Tiruchirapalli, R., and Taylor, S.: Measurements and products from the Solar Backscatter Ultraviolet (SBUV/2) and Ozone Mapping and Profiler Suite (OMPS) instruments, Int. J. Remote Sens., 30(15-16), 4259-4272, 2009.

Froidevaux, L., Jiang, Y. B., Lambert, A., Livesey, N. J., Read, W. G., Waters, J. W., Browell, E. V., Hair, J. W., Avery, M. A., McGee, T. J., Twigg, L. W., Sumnicht, G. K., Jucks, K. W., Margitan, J. J., Sen, B., Stachnik, R. A., Toon, G. C., Bernath, P. 
F., Boone, C. D., Walker, K. A., Filipiak, M. J., Harwood, R. S., Fuller, R. A., Manney, G. L., Schwartz, M. J., Daffer, W. H., Drouin, B. J., Cofield, R. E., Cuddy, D. T., Jarnot, R. F., Knosp, B. W., Perun, V. S., Snyder, W. V., Stek, P. C., Thurstans, R. P., and Wagner, P. A.: Validation of Aura Microwave Limb Sounder stratospheric ozone measurements, J. Geophys. Res., 113, D15S20, doi:10.1029/2007JD008771, 2008.

Grobner, J. and Kerr, J. B.: Ground-based determination of the spectral ultraviolet extraterrestrial solar irradiance: Providing a link between space-based and ground-based solar UV measurements, J. Geophys. Res., 106(D7), 7211-7217, 2001.

Kerr, J. B.: New methodology for deriving total ozone and other atmospheric variables from Brewer spectrophotometer direct sun spectra, J. Geophys. Res., 107(D23), 9pp., doi:10.1029/2001JD001227, 2002.

Kerr, J. B. and Davis, J. M.: New methodology applied to deriving total ozone and other atmospheric variables from global irradiance spectra, J. Geophys. Res., 112, D21301, doi:10.1029/2007JD008708, 2007.

Kerr, J. B. and McElroy, C. T.: Total ozone measurement made with the Brewer ozone spectrophotometer during STOIC 1989, J. Geophys. Res., 100, 9225-9230, 1995.

Kerr, J. B., McElroy, C. T., Wardle, D. I., Olafson, R. A., and Evans, W. F. J.: The automated Brewer spectrophotometer, in: Atmospheric ozone: Proceedings of the Quadrennial Ozone Symposium, edited by: Zerefos, C. S. and Ghazi, A., Reidel, Boston, Mass., 396-401, 1985.

Kimlin, M. G., Sabburg, J. M., Parisi, A. V., and Meltzer, R. S.: Comparison of Brewer spectrophotometer ultraviolet data from similar latitudes in the Northern and Southern Hemisphere, J. Atmos. Sol.-Terr. Phys., 65, 1401-1410, doi:10.1016/j.jastp.2003.09.003, 2003.

Kimlin, M. G., Slusser, J. R., Schallhorn, K. A., Lantz, K., and Meltzer, R. S.: Comparison of ultraviolet data from collocated instruments from the U.S. EPA Brewer Spectrophotometer Network and the U.S. Department of Agriculture UVB Monitoring and Research Program, Opt. Eng., 44, 041009, doi:10.1117/1.1885470, 2005.

Komhyr, W. D.: Slit functions for Dobson spectrophotometer 83, NOAA Air Resources Laboratory, Geophysical Monitoring for Climatic Change, Unpublished manuscript, Boulder, Colorado, 1982.

Komhyr, W. D. and Evans, R. D.: Operations handbook-ozone observations with a Dobson spectrophotometer, Global Ozone Research and Monitoring Project, Rep. 183, World Meteorological Organization, Geneva, Switzerland, 91 pp., 2006.

Komhyr, W. D., Grass, R. D., and Leonard, R. K.: Dobson spectrophotometer 83: a standard for total ozone measurements, 1962-1987, J. Geophys. Res., 94, 9847-9861, 1989.

Komhyr, W. D., Mateer, C. L., and Hudson, R. D.: Effective BassPaur 1985 Ozone Absorption Coefficients for Use With Dobson Ozone Spectrophotometers, J. Geophys. Res., 98(D11), 2045120465, 1993.

Lantz, K., Disterhoft, P., Early, E., Thompson, A., DeLuisi, J., Kiedron, P., Harrison, L., Berndt, J., Mou, W., Erhamjian, T. J., Cabausua, L., Robertson, J., Hayes, D., Slusser, J., Bigelow, D., Janson, G., Beaubian, A., and Beaubian, M.: The 1997 North American Interagency Intercomparison of Ultraviolet Monitoring Spectroradiometers, J. Res. Natl. Inst. Stand. Technol., 107,
19-62, 2002.

Lerot, C., Van Roozendael, M., van Geffen, J., van Gent, J., Fayt, C., Spurr, R., Lichtenberg, G., and von Bargen, A.: Six years of total ozone column measurements from SCIAMACHY nadir observations, Atmos. Meas. Tech., 2, 87-98, doi:10.5194/amt-2-872009, 2009.

Levelt, P. F., van den Oord, G. H. J., Dobber, M. R., Malkki, A., Visser, H., de Vries, J., Stammes, P., Lundell, J. O. V., and Saari, H.: The Ozone Monitoring Instrument, IEEE T. Geosc. Remote, 44(5), 1093-1101, 2006.

Liu, X., Chance, K., Sioris, C. E., and Kurosu, T. P.: Impact of using different ozone cross sections on ozone profile retrievals from Global Ozone Monitoring Experiment (GOME) ultraviolet measurements, Atmos. Chem. Phys., 7, 3571-3578, doi:10.5194/acp-7-3571-2007, 2007.

Malicet, C., Daumont, D., Charbonnier, J., Parisse, C., Chakir, A., and Brion, J.: Ozone UV spectroscopy, II: Absorption crosssections and temperature dependence, J. Atmos. Chem., 21, 263273, 1995.

Mateer, C. L. and DeLuisi, J. J.: A new Umkehr inversion algorithm, J. Atmos. Terr. Phys., 54, 537-556, 1992.

McPeters, R. D., Heath, D. F., and Bhartia, P. K.: Average ozone profiles for 1979 from the NIMBUS 7 SBUV instrument, J. Geophys. Res., 89, 5199-5214, 1984.

Miyagawa, K., Sasaki, T., Nakane, H., Petropavlovskikh, I., and Evans, R. D.: Reevaluation of long-term Umkehr Data and Ozone profiles, J. Geophys. Res., 15, 4043-4053, doi:10.1029/2008JD010658, 2009.

Munro, R., Eisinger, M., Anderson, C., Callies, J., Corpaccioli, E., Lang, R., Lefebvre, A., Livschitz, Y., and Pérez Albiñana, A.: GOME-2 on Metop: From in-orbit verification to routine operations, in: Proceedings of EUMETSAT Meteorological Satellite Conference, Helsinki, Finland, 12-16 June 2006.

Nair, P. J., Godin-Beekmann, S., Pazmiño, A., Hauchecorne, A., Ancellet, G., Petropavlovskikh, I., Flynn, L. E., and Froidevaux, L.: Coherence of long-term stratospheric ozone vertical distribution time series used for the study of ozone recovery at a northern mid-latitude station, Atmos. Chem. Phys., 11, 49574975, doi:10.5194/acp-11-4957-2011, 2011.

Orphal, J.: A critical review of the absorption cross-sections of $\mathrm{O}_{3}$ and $\mathrm{NO}_{2}$ in the ultraviolet and visible, J. Photochem. Photobiol., A, 157(2003) 185-209, doi:10.1016/S1010-6030(03)00061-3, 2003.

Petropavlovskikh, I., Bhartia, P. K., and DeLuisi, J.: New Umkehr ozone profile retrieval algorithm optimized for climatological studies, Geophys. Res. Lett., 32, L16808, doi:10.1029/2005GL023323, 2005a.

Petropavlovskikh, I., Kireev, S., Maillard, E., Stube, R., and Bhartia, P. K.: New Brewer algorithm for a single pair, GAW report 175, The Ninth Biennial WMO Consultation on Brewer Ozone and UV Spectrophotometer Operation, Calibration and Data Reporting, Delft, The Netherlands, 31 May to 3 June 2005, WMO TD No. 1419, pp. 25-27, 2005b.

Petropavlovskikh, I., Fioletov, V., Oltmans, S., Lantz, K., Kiedron, P., and Disterhoft, P.: The short-term and long-term tropospheric ozone variability available from zenith sky measurements, The Tenth Biennial WMO Consultation on Brewer Ozone and UV Spectrophotometer Operation, Calibration and Data Reporting, The Tenths Biennial Brewer User Meeting, edited by: McEl- 
roy, C. T. and Hare, E. W., Northwich, United Kingdom, 4 to 8 June 2007, WMO TD No. 1420, Global Atmosphere Watch report \#176, 2007.

Petropavlovskikh, I., Evans, R. D., Carbaugh, G. L., Maillard, E., and Stubi, R.: Towards a better knowledge of Umkehr measurements: A detailed study of data from thirteen Dobson intercomparisons, World Meteorological Organization Global Atmosphere Watch, GAW No. 180, 2008.

Petropavlovskikh, I., Evans, R. B., McConville, G., Miyagawa, K., and Oltmans, S.: Effect of the out-of-band stray light on the retrieval of the Umkehr Dobson ozone profiles, Int. J. Remote Sens., 30, 6461-6482, doi:10.1080/01431160902865806, 2009.

Paur, R. J. and Bass, A. M.: The ultraviolet cross-sections of ozone, II, Results and temperature dependence, in: Atmospheric Ozone, edited by: Zerefos, C.S., Ghazi, A., and Reidel, D., Norwell, Mass., 611-616, 1985.
Reinsel, G., Tiao, G. C., Lewis, R.: A Statistical Analysis of Total Ozone Data from the Nimbus-4 BUV Satellite Experiment, J. Atmos. Sci., 39, 418-430, doi:10.1175/15200469(1982)039;0418:ASAOTO ¿2.0.CO;2, 1982.

Rodgers, C. D.: Inverse Methods for Atmospheric Sounding: Theory and Practice, World Scientific, 238 pp., 2000.

Summers, M. E. and Sawchuck, W.: Zonally Averaged Trace Constituent Climatology. A Combination of Observational Data Sets and 1-D and 2-D Chemical-Dynamical Model Result, Naval Research Laboratory, Technical Report, NRL/MR/7641-93-7416, Washington, DC, 1993.

Van Hoosier, M. E.: Solar ultraviolet spectral irradiance with increased wavelength and irradiance accuracy, SPIE Proceedings 2831, 57-64, 1996.

WMO, Scientific Assessment of Ozone Depletion: 2006, Global Ozone Research and Monitoring Project, Report No. 50, Geneva: World Meteorological Organization, 2007. 